Revue d'histoire de l'Amérique française

REVUE D.HISTOIRE DE L'AMÉRIQUE FRANÇAISE

\title{
SAINTE-MARIE-ELEUTHÈRE, Soeur, c.n.d., La Mère dans le roman canadien-français. Les Presses de l'Université Laval, 1964.
}

\section{Michelle Le Normand}

Volume 18, numéro 2, septembre 1964

URI : https://id.erudit.org/iderudit/302373ar

DOI : https://doi.org/10.7202/302373ar

Aller au sommaire du numéro

Éditeur(s)

Institut d'histoire de l'Amérique française

ISSN

0035-2357 (imprimé)

1492-1383 (numérique)

Découvrir la revue

Citer ce compte rendu

Le Normand, M. (1964). Compte rendu de [SAINTE-MARIE-ELEUTHÈRE, Soeur, c.n.d., La Mère dans le roman canadien-français. Les Presses de l'Université Laval, 1964.] Revue d'histoire de l'Amérique française, 18(2), 293-295.

https://doi.org/10.7202/302373ar d'utilisation que vous pouvez consulter en ligne.

https://apropos.erudit.org/fr/usagers/politique-dutilisation/ 
SOEUR SAINTE-MARIE-EleuthÈre, C.N.D., La Mère dans le roman canadien-français. Les Presses de l'Université Laval, 1964.

L'auteur d'un roman à thèse a-t-il moins de mal à rassembler des faits plausibles pour prouver ce qu'il veut prouver, que le critique qui bâtit sa thèse sur un sujet choisi ? Probablement. Sœur Sainte-Marie-Eleuthère, dans son interprétation des textes sur La Mère dans le roman canadien-français, manifeste une ingéniosité remarquable, sauf pour quelques rares cas, où la psychanalyse joue un rôle trop compliqué et se perd à travers les mythes et les symboles. Ainsi pour le mythe de la chambre qui appellerait l'image de la mère. L'Auteur semble le proposer uniquement pour commenter le roman d'Anne Hébert: Les chambres de bois. Et certaines phrases dans cette étude jettent un malaise dans l'esprit, parce que c'est une religieuse qui les écrit. On fronce les sourcils, quand, à propos de la douteuse 
valeur morale, Sœur Sainte-Marie-Eleuthère écrit: "Le moraliste aura à juger si Catherine peut rompre son mariage avec Michel sans autre formalité que de rendre l'anneau"... Même malaise pour la conclusion. L'auteur parle d'une note d'espoir parce que "Anne Hébert laisse fuir sa Catherine des Chambres de bois". Ceux qui ne connaissent pas l'œuvre, n'y verront rien. Ceux qui l'ont lue, et les jeunes élèves qui la liront après avoir lu la thèse, sauront que Catherine ne fuit pas seule, et que pour voir "une note d'espoir" dans cette évasion, il faut approuver l'amour libre. Symbole ou mythe, ce livre est franchement mauvais. L'amant qui remplace le mari est une réalité. Et ajoutez-y l'aventure en cours, l'esprit qui l'anime, et la scène où, une vieille servante meurt "comme un chien", diraient nos gens, "parce que, ayant servi toute sa vie en ce bas-monde, elle ne veut pas risquer de servir Dieu dans l'autre". C'est d'ailleurs le seul endroit où le nom de Dieu paraît, dans cette histoire. Avec ou sans mythe, la mère ne compte pas plus que Dieu dans ce roman que S. Sainte-Marie-Eleuthère aurait pu ignorer. Puisque, en plus, Anne Hébert figure avec avantage, avec $L e$ Torrent, où la Mère est vraiment en cause. Dans ce cas, S. Sainte-Marie-Eleuthère signale l'absence du point de vue chrétien.

$\mathrm{Au}$ moment où justement, la religieuse nous dit: "que le roman canadien évolue vers une plus grande variété de sujets et une audace de plus en plus marquée dans l'expression des idées et dans les positions adoptées par la morale" qui préviendra les élèves des erreurs, si les religieuses démissionnent en faveur de l'art pour l'art?

Cette réserve est d'autant plus regrettable que la thèse de Sœur Sainte-Marie-Eleuthère est un travail magistral. Il nous gratifie d'une source unique de renseignements sur la période étudiée. L'A. choisit avec un goût sûr, les plus beaux textes. Ils sont variés, nombreux et démontrent la valeur de nos romanciers. Elle a su voir la beauté, la richesse de l'inspiration, et elle nous apprend que nos romanciers écrivent bien, observent bien, quel que soit leur genre. Elle nous fait prendre conscience de leur diversité. Elle nous apprend que leur style bien à eux dénote une authentique sensibilité.

Il faut féliciter Sœur Sainte-Marie-Eleuthère, la remercier d'avoir écrit ce livre. Le nombre d'œuvres valables est imposant, et cet inventaire remet en mémoire des romans qui ont eu peu de lecteurs et qui méritent mieux. Les textes choisis nous le font voir. 
Sœur Sainte-Marie-Eleuthère rend service et aux auteurs et aux lecteurs. Grâce aux intelligents commentaires, ces derniers apprécieront, comprendront mieux beaucoup de livres. Le seul reproche, c'est cette objectivité neutre pour des romans qui appellent des réserves parfois graves. Pour quelques romans, l'A. se prononce. Pour d'autres, elle semble n'avoir qu'un critère: "l'Art." Nos critiques officiels sont d'ordinaire des adeptes de cette formule. Une religieuse doit suivre un autre exemple. Pourquoi pas celui du Père André Blanchet, s.j., qui avec tant d'intelligence et de finesse juge les œuvres des plus grands romanciers français en n'oubliant jamais Dieu, la morale, le bon sens et le destin chrétien de l'homme?

Et puis, il y a le Pape. Ne vient-il pas d'écrire qu'il faut absolument vivre "la plénitude de sa vocation pour être immunisé contre les erreurs avec lesquelles le chrétien de nos jours entre en contact ?" 